\title{
Infection Control at a Government Hospital in Pakistan
}

\author{
Shehla Baqi ${ }^{1}$, Nizam Damani ${ }^{2}$, Sharaf Ali Shah ${ }^{3}$, Rafiq Khanani ${ }^{4}$ \\ ${ }^{1}$ Infectious Diseases, Sindh Institute of Urology and Transplantation, Karachi, Pakistan \\ ${ }^{2}$ Infection Prevention Control, Southern Health and Social Care Trust, Portadown, Northern Ireland (UK) \\ ${ }^{3}$ Bridge Consultants Foundation, Karachi, Pakistan \\ ${ }^{4}$ Pathology, Dow International Medical College, Karachi, Pakistan
}

doi:10.3396/ijic.V5i1.004.09

\begin{abstract}
An Infection Control survey of a government hospital in Pakistan was conducted in 2007. The hospital did not have an Infection Control committee or policies. Of 13 inpatient units, only the 2 ICUs had hand hygiene $(\mathrm{HH})$ facilities. Health care workers (HCWs) did not demonstrate hand hygiene during patient care. In the ICUs, gowns were shared amongst HCWs. Sharps were thrown in the garbage pail. Urinary catheter bags were emptied by janitors into patient garbage pails. Isolation precautions were not observed with patients of tuberculosis or multi-drug resistant organisms. The Dental clinic had no autoclave. In the Surgery clinic, over 50 proctoscopies were performed without disinfection. The Isolation Ward did not have $\mathrm{HH}$ or appropriate isolation facilities. In a spot survey of $86 \mathrm{HCWs}, 85 \%$ had sustained needle stick injuries. Correct Infection Control practices are not followed at the hospital. There is an urgent need to establish an Infection Control Programme.
\end{abstract}

\section{Key Words}

Infection Control, Hospital, Pakistan

\section{Introduction}

Healthcare associated infection is considered to be a major cause of morbidity and mortality. It is estimated to occur in $10 \%$ of patients in developed countries and $25 \%$ in countries with limited resources where Infection Control practices are often unsafe. ${ }^{1}$

Infection Control encompasses many aspects with hand hygiene as the single most important step in the prevention of spread of infection in the hospital setting. ${ }^{2,3,4}$ Personal protective equipment protects health care workers ( $\mathrm{HCWs}$ ) and reduces the spread of organisms. ${ }^{5}$ Transmission of infections in health care facilities can be prevented through application of standard and transmission based precautions. ${ }^{6}$

\section{Corresponding author}

Dr. Shehla Baqi, Associate Professor, Department of Infectious Diseases, Sindh Institute of Urology and Transplantation, Karachi, Pakistan, Mobile: 920345 6197447, Fax: 9221921 5469, Email: shehlabaqi@gmail.com 
Health care associated infections include intravascular catheter related sepsis, infection associated with urinary catheterization and ventilator associated pneumonia. Guidelines have been developed for their prevention. . $8,9,10,11$ An essential component of Infection Control is protection of hospital staff. ${ }^{12}$

Pakistan is divided into four provinces where health care is provided by a mix of public, private and charitable hospitals. Government hospitals provide free service to the public sector. We surveyed a government hospital serving poor patients in order to assess its state of Infection Control.

\section{Methodology}

An Infection Control survey of a government hospital was conducted in January of 2007 . It is a 1750 bedded tertiary teaching hospital with multiple inpatient units and a busy outpatient department. The hospital did not have an Infection Control Team or Committee.

\section{Inpatient Units}

The hospital has 40 inpatient units of which 13 were surveyed using audit tools. There are 3-5 inpatient units in each field of Medicine, Surgery, Paediatrics and Obstetrics/Gynaecology, numbered 1 up to 5. We visited one inpatient unit a day, starting with unit Number 1 of each discipline. At the visit, permission to conduct the survey was requested from the Head of the Unit. If the Head was not available, we visited the next Unit up in numerical order until two units in each discipline had been completed, totalling 8 . There are two ICUs and two special care units at the hospital, all four of which were included in the survey as well as the Emergency Room. Therefore 13 clinical units in all were surveyed.

Infection Control audit tools developed by the UK Infection Control Nurses Association and Department of Health for acute care were used with very minor modifications. ${ }^{13}$ The audit was carried out once in the morning. In each unit, a HCW was directly observed for compliance with hand hygiene recommendations while performing patient care. Hand hygiene facilities and the use and supplies of personal protective equipment were audited. Two health care workers in each unit who routinely placed peripheral IVs or performed urinary catheterization were asked to each describe one of the procedures. A third HCW in each of the two ICUs was asked to demonstrate ET suctioning. Overall 28 health care workers were thus audited for the above procedures.

Intravenous cannulation and injections, emptying of urinary catheter bags, ventilator care, environmental cleaning and disinfection, and disposal of sharps were audited. Finally, a spot survey was conducted of all health care workers and janitors present in each unit at the time of our visit to assess how many received hepatitis B immunization and if they had ever sustained a needle stick injury.

\section{Outpatient Department and Isolation Ward}

Infection control practices were surveyed in the Dental, Surgical and Chest \& Tuberculosis clinics as well as in the Isolation Ward but medical procedures were not audited.

\section{Results}

\section{A. Thirteen In-patient Units a. Hand Hygiene}

None of the units had a Hand Hygiene Policy. Handwashing sinks and alcohol rub dispensers at the site of patient care (at a ratio of 6 dispensers to 8 beds) were found in only the $2 \mathrm{ICU}$ s On direct observation of a HCW during patient care in each unit, none of 13 HCWs practiced hand hygiene.

\section{b. Personal Protective Equipment}

None of the units had policies on Personal Protective Equipment. The senior nurse was asked about supplies.

i. Gloves: Sterile gloves were in adequate supply in five, and clean latex gloves in 1 of 13 units. Polyethylene (PE) gloves were in adequate supply due to low cost.

ii. Gowns: Supply of non-disposable cotton gowns was inadequate in all units. In the two Intensive Care Units, the same gown was shared between HCWs, worn from one patient to another, and laundered on alternate days.

iii. Masks: Seven of 13 units reported that they had surgical masks. N95 masks for airborne precautions were not available. 


\section{c. Peripheral Intravenous Cannulation and IV Injection of Fluids/Medications}

Of 13 HCWs, 12 described IV cannulation whereas 1 demonstrated the procedure. None mentioned hand hygiene, 11 said that they apply alcohol to the patient's skin. In the 1 actual cannulation, no hand hygiene was practiced, no alcohol applied, gloves were not used and the cannula was placed on the child's bed between repeated attempts. Cannulas were removed from sterile packaging in all units. Recapping using both hands was practiced by 12 of $13 \mathrm{HCWs}$.

Hypodermic needle was found left in the intravenous infusion fluid bag in 8 of 13 units. A new single use needle/syringe was used to draw up the medication as well as to inject it in 7 units but was often multiple use in the special care units, ICUs and Emergency ward. In all units, needles and syringes were discarded in the garbage pail rather than sharps boxes.

\section{d. Urinary Catheterization}

A health care worker in each unit was asked to describe the procedure of urinary catheterization. Hand hygiene was not mentioned by any HCW. Sterile gloves during insertion were mentioned by three out of 13 . Single use lubricant was mentioned in 3 units, multiple use in 8 and none in 2 units. Urinary catheters were single patient use in all units.

Urinary catheter bags were emptied by janitors who were observed emptying urinary bags of 2 patients in turn. No hand hygiene between patients was practiced. Disinfected jug was not used. Eight out of 13 janitors wore PE gloves. Receptacles were shared between patients in 11 of 13 units, and included the patients' garbage cans in 11 (Figure 1). Contact between the tap and the receptacle was not avoided. The urinary bag was found touching the floor in 6 of 13 units.

Urine was not sampled from the port. The system was disconnected or the bag used to obtain urine specimens, usually by janitors or the family member attending to the patient.

\section{e. Ventilator Associated Pneumonia - Audit of two Intensive Care Units}

Senior staff nurses reported that the ventilator tubing and endotracheal airway was always disposable and single patient use. Laryngoscopes were cleaned but not disinfected in one unit and disinfected with alcohol in another. Ventilator was reportedly decontaminated between patients and the filter changed but no record of the cleaning service was available. Boiled water was used for humidification but stored in bottles that were not disinfected. Each bed had its own suction bottle.

We chose a ventilated patient on the first bed of each of the 2 units. Both were propped up. Both had nasogastric tubes. On observation of ET suctioning, no hand hygiene was practiced before or after suctioning by either of the two health care workers, one of whom wore PE gloves. ET suction catheter was single use in one unit, but reused in the other.

Both patients were on multiple antibiotics for ventilator associated pneumonia (VAP).

\section{f. Isolation Precautions}

Isolation precautions were not implemented for patients with pulmonary tuberculosis or multi-drug resistant organisms in any of the units.

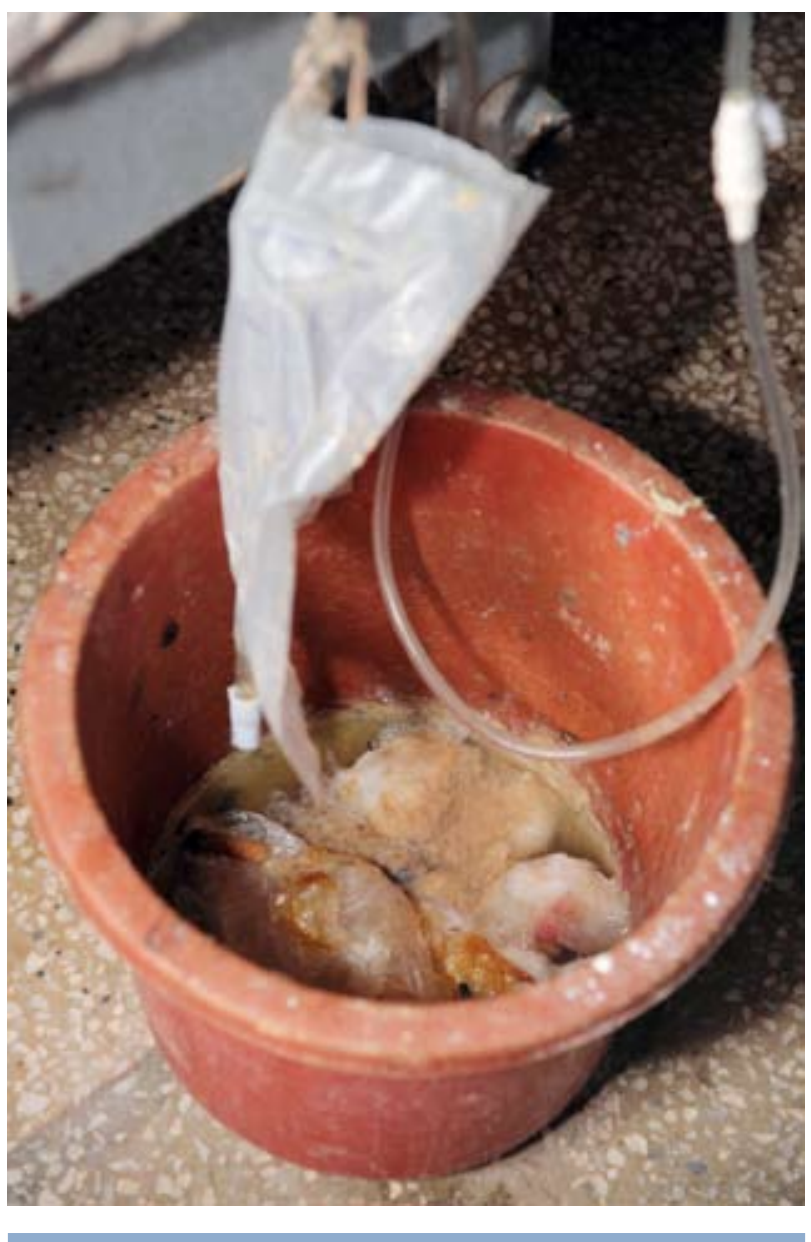

Figure 1. Patient urinary bag draining into waste bucket 


\section{g. Environmental Cleaning and Disinfection}

All 13 clinical areas were routinely swept with a broom. Mopping was done with water and disinfectant in 11 units, and water with disinfectant plus detergent in two. A phenolic disinfectant was used in all cases; additionally bleach in six and formaldehyde in two. None of the janitors knew what volumes or concentrations of disinfectants they used. The mop was washed with bleach after use in three of 13 units. Dry dusting was done in all units. After patient discharge or expiry, furniture and mattresses were cleaned with a damp cloth in 9 of 13 units. Plastic covering of the mattresses was torn in 10 of 13 units.

Single patient use thermometers were used in 4 of 13 units. Except in the ICUs; oxygen masks, tubing and nebulizers were shared between patients. In all units, oxygen flow meters, humidifiers and nebulizers were not disinfected and had caked residue. Cotton balls soaked in alcohol were found in every unit and reportedly changed daily. Patient's liquid waste was emptied in the staff toilet in two units, and in the patient's toilets in 11 units. Solid waste was not segregated, put in blue bags and taken to an open dump by the roadside outside the hospital (Figure 2).

\section{h. Sharps Disposal and Sharps Injuries}

Needle cutters were in use in 9 of 13 units and its contents emptied into garbage bags.
Sharps boxes were not available in any unit. None of the units had a written procedure for managing health care workers with blood exposures.

Of a total of $86 \mathrm{HCWs}, 60 \%$ had completed hepatitis $B$ vaccination. $85 \%$ had sustained needlestick injuries. Of note was the Emergency Room, a major trauma centre, where none of $14 \mathrm{HCWs}$ had received Hepatitis B immunization and 13 had sustained needle-stick injuries. Not one senior physician in any of the units knew fully the correct procedure to follow after a needlestick injury. Of 15 unit janitors surveyed, none had received Hepatitis B vaccination and all had sustained needlestick injuries while collecting hospital waste.

\section{B. Outpatient Department}

\section{a. Dental Clinic}

Dental instruments were washed with tap water, and then placed for 30 minutes in a Hot Box Table Top Oven which was over a decade old, with no temperature gauge. Once a week, dental instruments were placed in glutaraldehyde. Of two dental workers observed during a procedure, one did not wear gloves, and the other wore polyethylene gloves. Neither of the two practiced hand hygiene, wore masks or eye protection gear. Disposable needles and single use cartridges were used. Needles were disposed of in the garbage pail.

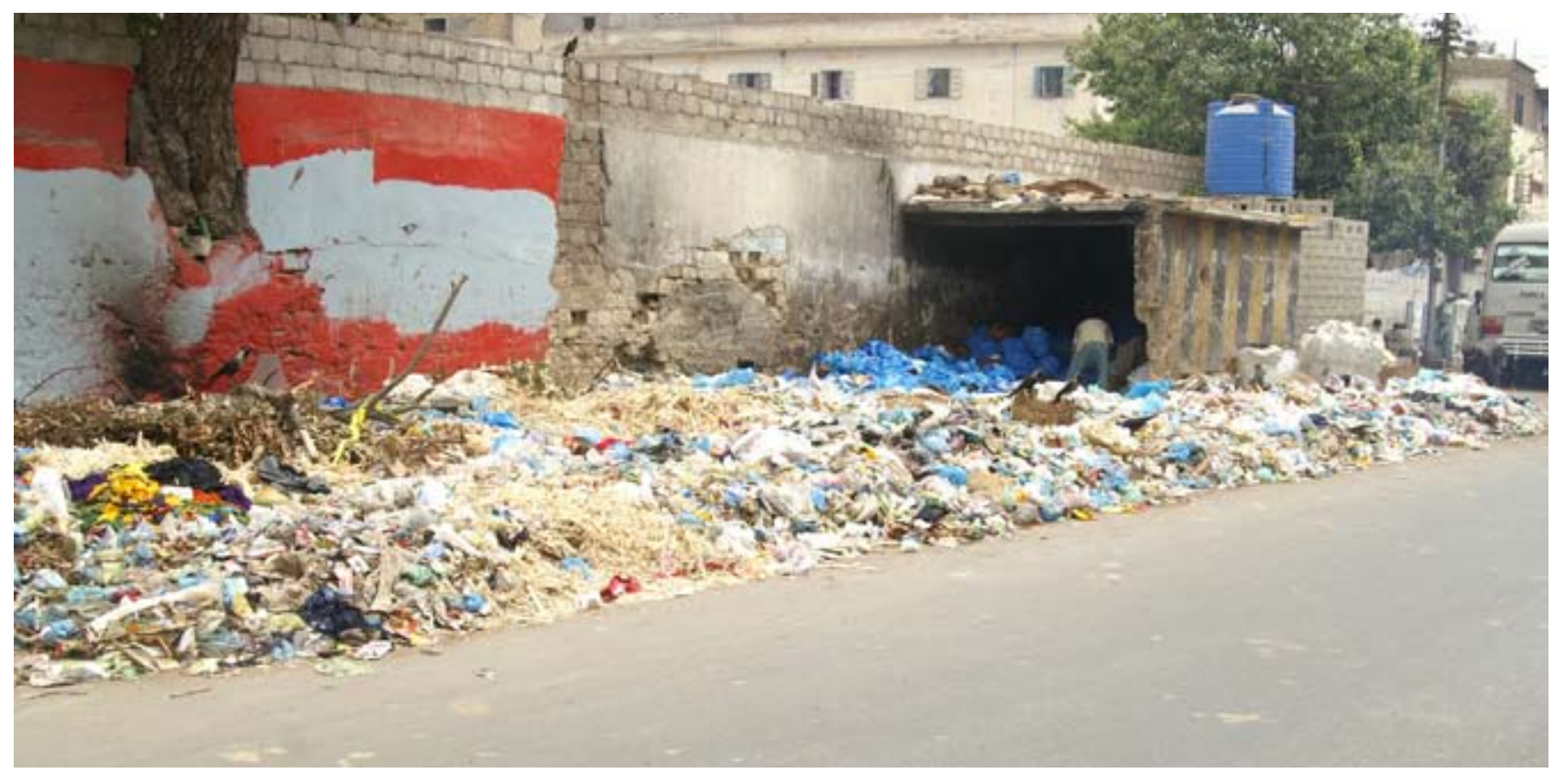

Figure 2. Hospital waste along the hospital wall by the roadside 


\section{b. Surgical Clinic}

Surgical OPD is held 6 days a week. On the day of the survey, over 50 proctoscopies were performed. Only 2 proctoscopes were available. They were not disinfected between patients (Figure 3). The room for wound care and dressing appeared dirty with no hand hygiene facility. The dresser did not practice hand hygiene. Sterile dressings were not used.

\section{c. Chest and TB Clinic}

Surgical masks were not provided to coughing patients. Chest physicians were not protected with N95 masks.

\section{Survey of the Isolation Ward}

There were no handwashing facilities for the staff. Alcohol rub was only available at the nurse's desk. There were no single rooms or rooms with negative pressure. Window screens were not intact. Latex gloves, gowns, surgical masks and caps were in good supply, but not N95 masks. Infectious waste and sharps were not disposed of safely.

\section{Discussion}

Correct Infection Control practices are not being followed in the areas surveyed. These findings are likely to be representative of not only the rest of the hospital, but other government hospitals throughout the country. However, similar surveys from other public or private hospitals in Pakistan are not available with which to compare our data. Infection Control awareness is generally lacking throughout the healthcare system in Pakistan. Government hospitals often have poorer standards of Infection Control since they have limited resources, serve people of a lower socio-economic strata and have high patient volumes. Moreover, there are no mechanisms in place in Pakistan for monitoring and quantifying the incidence of healthcare related infections in public, private and charitable hospitals, which would be useful data towards increasing awareness.

Absence of hand hygiene may be due to inadequate hand hygiene facilities, low staff to patient ratios, lack of time, insufficient knowledge including misconceptions regarding alcohol rub, and casual attitudes towards infection control. ${ }^{14,15,16,17}$ Programmes to improve compliance with hand hygiene must be undertaken, and alcohol rubs made available. ${ }^{18,19,20}$
Supplies of personal protective equipment are not sufficient. PE gloves are cheaper than clean latex gloves but not recommended for infection control use. ${ }^{21} \mathrm{~N} 95$ masks should be available for contact with patients of pulmonary tuberculosis. ${ }^{22}$ Gowns must not be shared between health care workers or worn from patient to patient since that provides an easy means for the spread of infection.

Aseptic technique during intravenous catheter insertion and urinary catheterization is essential and hand hygiene must be emphasized. ${ }^{9,23}$ Janitors must not empty the urinary bags. If this is unavoidable due to shortage of nursing staff, then janitors must receive training in Infection Control. Urine should be emptied into a disinfected jug, which must not be shared. Urine samples should be obtained from the port or sampling sleeve.

Disinfection of humidifiers must be done, and oxygen masks, tubing and nebulizers should be single patient use. Thermometers should be single patient use or disinfected between patients. A high incidence of VAP has been reported. ${ }^{24}$ Lack of hand hygiene, reused gowns and non-sterile humidifier water may be contributory factors.

Standard and transmission based isolation precautions are not being followed and this is due to absence of an Infection Control infrastructure in the hospital. Contact precautions are required for patients with multi-

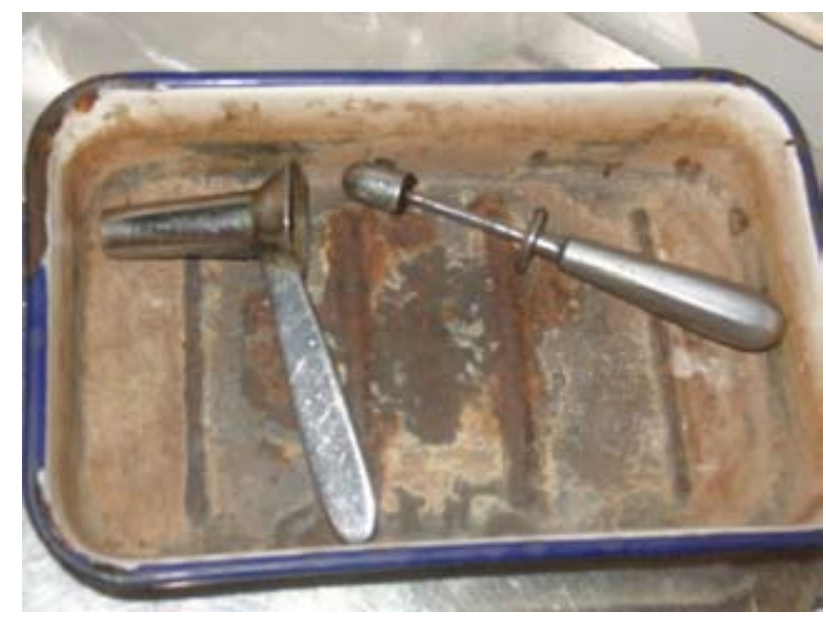

Figure 3. Proctoscopes in surgery clinic that are not disinfected between patients 
drug resistant organisms. Patients with pulmonary tuberculosis should be placed in a single room with good ventilation as well as exhausting air externally. ${ }^{25} \mathrm{~A}$ negative pressure room is required if MDR tuberculosis is suspected.

Sweeping with a broom in clinical areas is not recommended, a dry mop being preferable. The floor should be cleaned with detergent and water. Money saved by not using routine disinfectant can be diverted to alcohol hand rubs and PPE. It is of concern that janitors were unaware of the concentrations and properties of the potentially harmful disinfectants that they were routinely using. Phenol can be absorbed through the skin and cause hyperbilirubinemia in infants. Formalin is a potent gaseous fumigant and eye and nasal irritant and must not be used as an environmental disinfectant. It would be cheaper, safer and more reliably microbiocidal to use bleach products with easy dilution instructions.

Disinfection and sterilization must be a priority. Dental OPD must be provided with dental autoclaves and surgical OPD needs proctoscopes which should be disinfected between patients. ${ }^{26}$

Pakistan has a high seroprevalence of HBV and HCV with a high incidence in health care workers. ${ }^{27} \mathrm{HIV}$ is on the rise in Pakistan, the epidemic being fueled by injecting drug use. ${ }^{28}$ The high occurrence of needle stick injuries in hospital staff found in this survey has also been documented in other studies. ${ }^{29}$ Health care workers need education and training in the prevention of sharps injuries, and taught the one-handed scoop technique if recapping of the needle cannot be avoided, as is the case in many hospitals in Pakistan where samples are sent in syringes rather than tubes in order to save cost. Otherwise, needle and syringe should be discarded as a single unit in a sharps container. Given our limited resources, empty thick cardboard cartons of hospital supplies can be turned into sharps boxes, and incinerated when three-quarters full. Needle Stick Injury Policy must be available in all units. ${ }^{30}$

It is not acceptable that only $60 \%$ of the HCWs surveyed were immunized against Hepatitis B. The janitorial staff appear to be the most vulnerable to needle stick injury but the least protected.
Although the survey appears bleak, there is at present an opportunity to make a change in age old sub-standard practices. The Ministry of Health, the Medical University and the administration of the hospital have expressed their commitment towards Infection Control in the hospital surveyed. The establishment of an Infection Control Committee is essential which, in government hospitals, should include a physician trained in Infectious Diseases, Infection Control Nurses in a ratio of at least 1 nurse to 200 beds, Infection Control Practitioners preferably with a background in Microbiology, the Medical Superintendent, the Chairman of the Board of Governors, heads of clinical departments, Chief Engineer and Head of Housekeeping. If the hospital has an attached Medical University, the Vice Chancellor of the University or his representative should also be a member of the committee. Minutes of the meetings should be sent to the Ministry of Health, from whom a representative should be requested to become a member as well. Government hospitals should participate.

To fight the spread of health care-associated infections which take a high toll in human lives and affect hundreds of millions of patients worldwide each year, $\mathrm{WHO}$ and its partners have launched the Global Patient Safety Challenge with the theme "Clean Care is Safer Care". ${ }^{31}$ Government hospitals in Pakistan should become a part of this campaign, which, together with educational programs for HCWs, construction of proper isolation rooms and purchase of hand hygiene and disinfection products will lead to a safer environment.

\section{Source of Funding}

Dow University of Health Sciences

\section{References}

1. Damani N. Simple measures saves lives: An approach to Infection Control in developing countries. Journal of Hospital Infection 2005: 65(S2);151-154.

2. Healthcare Infection Control Practices Advisory Committee. Guideline for Hand Hygiene in Health-Care Settings. Morbidity and Mortality Weekly Report 2002; 51(RR-16):1-45

3. Larson EL. APIC guideline for handwashing and hand antisepsis in health care settings. American Journal of Infection Control 1995; 23: 251-269.

4. Larson E. A causal link between hand washing and risk of infection? Examination of the evidence. Infection Control and Hospital Epidemiology 1988; 9: 28-36.

5. Centers for Disease Control and Prevention. Guidelines for infection control in health care personnel.1998. 
6. Garner JS, and the Hospital Infection Control Practices Advisory Committee. Guideline for isolation precautions in hospitals. Part II. Recommendations for isolation precautions in hospitals. 1997.

7. Infection Control Nurses Association. Guidelines for preventing intravascular catheter-related infection. UK: Infection Control Nurses Association, 2001.

8. Elliot TSJ, Faroqui MH, Armstrong RF, Hanson GC. Guidelines for good practice in central venous catheterization. Journal of Hospital Infection 1994; 28(3):163-176.

9. Deckhouse KD, Garibaldi RA. Prevention of CatheterAssociated Urinary Tract Infections. In: Abrutyn E, Goldmann DA, Scheckler WE, Eds. Saunders Infection Control Reference Service, 2nd edn. Philadelphia: WB Saunders Co. 2001; 257 262.

10. Kollef $\mathrm{MH}$. The prevention of ventilator-associated pneumonia. The New England Journal of Medicine 1999; 340(8): 627633.

11. Tablan OC, Anderson LF, Arden NH, et al. Guideline for the prevention of nosocomial pneumonia. Infection Control and Hospital Epidemiology 1994; 15: 587-627.

12. Bolyard EA, Tablon OC, Williams WN, et al. CDC guideline for infection control in healthcare personnel, 1998. American Journal of Infection Control 1998; 26(3): 289-354.

13. UK Dept. of Health and ICNA. Audit tools for monitoring infection control standards 2004 (Book and CD ROM). Bathgate: Infection Control Nurses Association, 2004.

14. Albert RK, Condie F. Hand-washing patterns in medical intensive care units. New England Journal of Medicine 1998; 24: $1465-1466$.

15. Bischoff WE, Reynolds TM, Sessler $\mathrm{CN}$ et al. Handwashing compliance by health care workers. The impact of introducing an accessible, alcohol based hand antiseptic. Archive of Internal Medicine 2000; 160: 1017-1021.

16. Larson E, Kretzer EK. Compliance with handwashing and barrier precautions. Journal of Hospital Infection 1995; 30 (Suppl): 88-106.

17. Boyce JM. Using alcohol for hand antisepsis: dispelling old myths. Infection Control and Hospital Epidemiology 2000; 21: 438-441.

18. Pittet D. Improve compliance with hand hygiene in hospitals. Infection Control and Hospital Epidemiology 2000; 21: 381 386.

19. Pittet D, Hugonnet $S$, Harbarth $S$, et al. Effectiveness of a hospital-wide programme to improve compliance with hand hygiene. The Lancet 2000; 356: 1307-1312.
20. Teare EL, Cookson B, French G, et al. UK Handwashing Initiative. Journal of Hospital Infection 1999; 43: 1-3.

21. Damani NN. Hand Hygiene and Personal Protective Equipment. In: Manual of Infection Control Procedures, 2nd edn.

22. Willeke K, Yinge Qian. Tuberculosis Control through Respirator Wear: Performance of National Institute of Occupational Safety and Health-Regulated Respirators. American Journal of Infection Control 1998; 26: 139-142.

23. Falkiner FR. The insertion and management of indwelling urethral catheter-minimizing the risk of infection. Journal of Hospital Infection 1993; 25: 79-90.

24. Rizvi MF, Hasan Y, Memon AR, et al. Pattern of nosocomial infection in two intensive care units of a tertiary care hospital in Karachi. Journal of College of Physicians and Surgeons of Pakistan 2007; 17(3): 136-139.

25. Harries AD, Maher D, Nunn P. Practical and affordable measures for the protection of health care workers from tuberculosis in low-income countries. Bulletin of the World Health Organisation 1997; 75(5): 477-489.

26. Rutala WA. APIC Guidelines Committee. APIC guideline for selection and use of disinfectants. American Journal of Infection Control 1996; 24: 313-342.

27. Aziz S, Memon A, Tily HI, et al. Prevalence of HIV, hepatitis $\mathrm{B}$ and $\mathrm{C}$ amongst health workers of Civil Hospital Karachi. Journal of the Pakistan Medical Association 2002; 52(3): 9294.

28. Rehman N, Emmanuel F, Akhtar S. HIV transmission among drug users in Larkana, Pakistan. Tropical Doctor 2007; 37(1): 58-59.

29. Mujeeb SA, Khatri Y, Khanani R. Frequency of parenteral exposure and seroprevalence of HBV, HCV and HIV among operation room personnel. Journal of Hospital Infection 1998; 38(2): 133-137.

30. Gerberding JL. Management of occupational exposures to blood-borne viruses. New England Journal of Medicine 1995; 332: 444-451.

31. World Health Organization. Clean Care is Safer Care: Countries and regions committing to support healthcareassociated infection. Available from: URL: http:/www.who.int/ gpsc/statements/en/index.html (Accessed February 20, 2009). 